\title{
Aphid honeydew: An arrestant and a contact kairomone for Episyrphus balteatus (Diptera: Syrphidae) larvae and adults
}

\author{
Pascal D. Leroy ${ }^{1}$, Raki AlMOHAMAD ${ }^{1 *}$, Sabrine ATTIA², Quentin CAPELla ${ }^{1}$, François J. VerhegGen ${ }^{1}$, \\ ERIC HAUBRUGE ${ }^{1}$ and FRÉDÉRIC FRANCIS ${ }^{1}$
${ }^{1}$ Department of Functional and Evolutionary Entomology, University of Liège, Gembloux Agro-Bio Tech, Passage des Déportés 2, 5030 Gembloux, Belgium; e-mails: almohamad75@yahoo.fr; leroy.pl@gmail.com; capella.quentin@gmail.com; fverheggen@ulg.ac.be; E.haubruge@ulg.ac.be; Frederic.francis@ulg.ac.be
${ }^{2}$ Department of Analytical Chemistry, University of Liège, Gembloux Agro-Bio Tech, Passage des Déportés 2, 5030 Gembloux, Belgium; e-mail: sabine_bios5@yahoo.fr

Key words. Diptera, Syrphidae, Episyrphus balteatus, Acyrthosiphon pisum, searching behaviour, adults, honeydew, kairomone, larvae

\begin{abstract}
Predator searching efficiency increases in response to a variety of environmental cues associated with its prey. The sugary excretion of aphids (honeydew) has been found to act as a prey-associated cue for many aphid natural enemies. In the present study, the honeydew excreted by Acyrthosiphon pisum (Harris) was identified as an arrestant and a contact kairomone for young larvae and adults of a common predatory hoverfly, Episyrphus balteatus (De Geer) (Diptera: Syrphidae). First and second instar larvae increased their foraging behaviour in the honeydew-treated area. When plants were sprayed with crude honeydew, the speed of movement of female E. balteatus was significantly higher than in controls, resulting in a longer period of time spent on treated plants and laying eggs. We conclude that the honeydew excreted by A. pisum induces searching behaviour and acts as and arrestant not only for adults but also for young E. balteatus larvae.
\end{abstract}

\section{INTRODUCTION}

Homopteran insects, including aphids, excrete copious amounts of honeydew comprised of substances derived from both the host plant and the insect itself (i.e. specific sugars and amino acids) (Heidari \& Copland, 1993; Leroy et al., 2011). Many studies have shown that this excretory product acts as an attractant for the adult stage of predators and parasitoids, such as Chrysopidae (McEwen et al., 1993; Petersen \& Hunter, 2002), Coccinellidae (Evans \& Dixon, 1986; Evans \& Richard, 1997), Syrphidae (Budenberg \& Powell, 1992; Shonouda, 1996; Bargen et al., 1998; Shonouda et al., 1998a, b; Sutherland et al., 2001) or Aphidiidae (Budenberg, 1990; Budenberg et al., 1992; Du et al., 1997). These studies demonstrated that aphid honeydew induces oviposition and increases localisation of hosts or prey. Many predators and parasitoids use this excretory product as a food complement rich in sugars (mono-, diand trisaccharides), and essential amino acids, also containing minerals, vitamins and organic acids (Wäckers, 2000).

It is well known that the aphidophagous syrphid Episyrphus balteatus (De Geer) (Diptera: Syrphidae) is an efficient predator of many aphid species in agro-ecosystems and in natural habitats (Tenhumberg \& Poehling, 1995). Females generally oviposit near aphid colonies to provide a food source for the emerging larvae which are unable to move any great distance $(<1 \mathrm{~m})$ to search for prey (Chandler, 1968a, b; Scholz \& Poehling, 2000; Sadeghi \& Gil- bert, 2000). Interestingly, Gries (1986) noted that newly emerged syrphid larvae stretch their papillae for better perception of prey-associated odours which induce a search behaviour: after fixing its anal end to the surface, the larva raises the rest of its body: it touches the surface with its mouthparts before choosing a new direction (Bhatia, 1939).

Previous studies have been focused on the potential odorant cues that enable E. balteatus females to locate and select suitable oviposition sites (Almohamad et al., 2007, 2008a, b; Verheggen et al., 2008, 2009), taking into consideration that the quality of an oviposition site can depend not only on the presence of aphids and their numbers, but also on the presence of inter- or intraspecific competitors (Almohamad et al., 2009, 2010). Nevertheless, little information is available about the role of honeydew-derived chemical cues in foraging behaviour by predatory hoverfly $E$. balteatus larvae, a crucial aspect of their effective use in strategies for the biological control of aphids.

The presence of aphids is always associated with the presence of large amount of honeydew on the host plant, contaminating peripheral plant parts such as leaves and stems (Buckley, 1987). This strongly suggests that syrphid larvae are often in contact with aphid honeydew. To complete our knowledge and to understand the role of aphid honeydew semiochemicals in the foraging behaviour of syrphids (larva or adult), we note that the behaviour of aphid predators on honeydew-contaminated plants suggests that honeydew could acts as an arrestant as well as a searching stimulant. An arrestant may be defined as a

\footnotetext{
* Corresponding author.
} 
chemical that results in insect aggregation as a result of indirect kinetic reactions, either the slowing down or stopping of locomotion (orthokinesis) (Shorey, 1977; Wickremasinghe, 2007). Contact kairomones affect host recognition by insect predators or parasitoids, and often elicit changes in searching efficiency and oviposition (e.g. Muratori et al., 2006; Hatano et al., 2008). We investigated the effect of honeydew on all three larval instar of $E$. balteatus to test the hypothesis that young emerging larvae as well as older ones are immediately in contact with honeydew and that this could induce foraging behaviour. We also tested the responses of ovipositing females.

\section{MATERIAL AND METHODS}

\section{Plant and insect rearing}

Broad-bean plants (Vicia faba L.) were grown in $9 \times 8 \mathrm{~cm}$ plastic pots filled with a mixture of vermiculite and perlite $(1 / 1)$ and maintained in a climate-controlled room (16 h light photoperiod; $60 \pm 10 \%$ RH; $20 \pm 2{ }^{\circ} \mathrm{C}$ ). Aphids (Acyrthosiphon pisum Harris) were reared on these broad-bean plants. In the same climatic conditions, adult Episyrphus balteatus were reared in $75 \times 60 \times 90$ $\mathrm{cm}$ cages provided with bee-collected pollen, sugar and water. Broad-bean plants infested with A.pisum were introduced into the cages for $3 \mathrm{~h}$ every two days to induce oviposition. Larvae were mass-reared in aerated plastic-boxes $(110 \times 140 \times 40 \mathrm{~mm})$ and fed daily ad libitum with $A$. pisum. Syrphid pupae were provided by Katz Biotech AG (Baruth, Germany).

\section{Effect of aphid honeydew on the foraging behaviour of syrphid larvae}

To assess the influence of aphid honeydew on E. balteatus larvae, fresh $A$. pisum honeydew was collected using microcapillaries $(2 \mu 1)$ on aluminium sheets placed under well-infested $V$. faba plants. Plastic discs were used in all behavioural experiments, made to fit into Petri dishes $(\varnothing=9 \mathrm{~cm})$. because they allowed us to work as close as possible to natural conditions without using any actual plant material. Half of a plastic-disc was covered with homogeneous droplets of a total of $50 \mu \mathrm{l}$ of honeydew, approximating natural levels on plant leaves. A neutral zone $(\varnothing=1$ $\mathrm{cm})$ was defined in the centre of the Petri dish to place the larvae at the start of each trial (Fig. 1). Larva passes through three instars, distinguished either visually (by observing the moults) or morphologically (from their mouthparts) (Bhatia, 1939; Ngamo \& Hance, 1998). The mouthparts of the first instar consist of a pair of elements joined together by the entire anterior side of basal sclerite, they lack triangular sclerites and the basal sclerite branches are not bifurcated. In the second instar, the two elements composing the mouthparts are well separated and linked only by the labrum and the labium, and the triangular sclerites are present. In the third instar the two elements of the basal sclerites have only one point of contact, and are separate and strongly sclerotised; the triangle sclerites are well sclerotised, and are oriented to the rear.

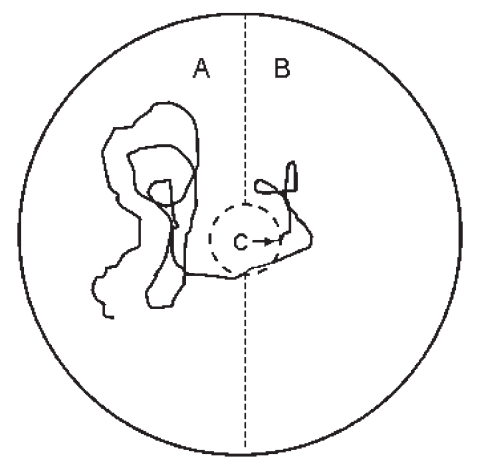

Fig. 1. An example of the locomotory path of E. balteatus larvae in a Petri dish for $10 \mathrm{~min}$. A - treated-zone with $50 \mu \mathrm{l}$ of A. pisum honeydew; $\mathrm{B}$ - clean-zone; $\mathrm{C}$ - neutral zone (larvae departure).

Each larva was placed in a Petri dish $(9 \mathrm{~cm})$ containing wet paper to maintain humidity for $6 \mathrm{~h}$ without aphids prior to testing. Then the larva was introduced to the experimental arena using a soft brush and its foraging behaviour recorded for $10 \mathrm{~min}$ using the software Observer 5.0 (Noldus Technology, The Netherlands) in each zone (treated and untreated). All observed behavioural categories are described in Table 1. Movement was measured by tracing the path on a transparent paper placed above the top of the petri dish. The first zone chosen by each larva was noted and the distance travelled measured using the trace. These observations were conducted in a climate-controlled room $\left(22 \pm 2^{\circ} \mathrm{C} ; 60-70 \%\right.$ $\mathrm{RH} ; 2,300$ lux). Fifteen syrphid larvae were tested individually.

\section{Effect of aphid honeydew on the oviposition behaviour of} syrphid female

To investigate the E. balteatus female response to aphid honeydew, A. pisum honeydew was collected as described above. The experiment was started by introducing a single gravid female into a net cage $(30 \times 30 \times 60 \mathrm{~cm})$ in the presence of one $V$. faba plant (15-20 cm; 2 leaves) treated with $50 \mu 1$ of crude honeydew. An untreated $V$. faba plant was used as negative control. We recorded foraging and oviposition behaviour (see Table 2 for categories) for $10 \mathrm{~min}$ using Observer 5.0 (Noldus Technology, The Netherlands). The eggs laid on each plant were then counted after the first $10 \mathrm{~min}$. The behavioural observations were conducted in an air-conditioned room at $22 \pm 2{ }^{\circ} \mathrm{C}$ and $60-70 \% \mathrm{RH}$. Females were 15-20 days old, mated and gravid: they had not previously been exposed to honeydew, nor during the previous $24 \mathrm{~h}$ been induced to oviposit. This experiment was replicated 15 times for each treatment.

\section{Statistical analysis}

One-way analysis of variance (ANOVA, General Linear Model) was required to compare the different behavioural observations of syrphid larvae or adults in presence and absence of honeydew. The directional preference of syrphid larvae between two zones (control, treated with honeydew) was compared using Chi-

TABLE 1. Description of behavioural events recorded for E. balteatus larvae.

\begin{tabular}{ll}
\hline Observed behaviour & Description behaviour \\
$\begin{array}{l}\text { Immobility } \\
\text { Moving (= Casting) }\end{array}$ & $\begin{array}{l}\text { Larva is stationary in the Petri dish more than 20 s without presenting any behaviour. } \\
\text { Larva moves in the Petri dish without stopping (= lateral movements of the larval thorax). }\end{array}$ \\
\hline Arresting and searching & \\
\hline Arrestment & $\begin{array}{l}\text { After moving, larva briefly stops (not more than } 5 \mathrm{~s} \text { ) to touch and perceive the surface of the Petri dish with } \\
\text { its mouthparts. } \\
\text { Searching }\end{array}$ \\
$\begin{array}{l}\text { After arrestment, larva fixes its anal end on the Petri dish, raises the rest of its body and balances its thorax } \\
\text { laterally (Bathia, 1939). }\end{array}$ \\
\hline
\end{tabular}


TABLE 2. Description of the behavioural events recorded for the E. balteatus female.

\begin{tabular}{ll}
\hline Observed behaviour & Description of behaviour \\
\hline Immobility & Female is stationary in the cage. \\
Searching & Female flies in the cage, or flies near the host-plant \\
Arrestment and acceptance & Female lands, moves and extends its proboscis to touch and perceive on the plant. \\
Oviposition & Female exhibits an abdominal protraction, deposits its ovipositor, and lays an egg on the host-plant. \\
\hline
\end{tabular}

squared test. All statistical tests were conducted using Minitab ${ }^{\circledR}$ release v. 15 .

\section{RESULTS}

\section{Effect of aphid honeydew on the foraging behaviour of syrphid larvae}

Our behavioural observations showed that $80 \%$ of the first instar larvae tested immediately after hatching orientated themselves to the zone containing honeydew: a significant difference was observed between the two zones (control, treated with honeydew) $\left(x^{2}{ }_{1}=5.72 ; \mathrm{P}=0.017\right)$. For second and third instar larvae, no directional preference was observed: $60 \%$ of the second instar larvae $\left(x^{2}=0.40\right.$; $\mathrm{P}=0.526)$ and $53 \%$ of the third instar larvae $\left(x^{2}=0.04\right.$; $\mathrm{P}=0.833$ ) chosed the aphid honeydew treated-zone.

The distance travelled by the first and second instar larvae in the honeydew treated area was significantly greater than in the non-treated area $\left(\mathrm{F}_{1,28}=4.72 ; \mathrm{P}=0.038\right.$ and $\mathrm{F}_{1}$, ${ }_{28}=4.79 ; \mathrm{P}=0.037$, respectively). Although the highly mobile third-instar larvae travelled the greatest distances, their movement paths were equivalent in the two zones with or without aphid honeydew $\left(\mathrm{F}_{1,28}=0.04 ; \mathrm{P}>0.05\right)$ (Fig. 2).

In terms of larval behaviour (immobility, moving and searching), significant differences were observed for the first and second instars whereas no significant differences were observed for the third instar larvae (Fig. 3). The honeydew-treated zone induced higher frequencies of walking by the first and second instars $\left(\mathrm{F}_{1,28}=3.76 ; \mathrm{P}=0.044\right.$ and $\mathrm{F}_{1,28}=5.36 ; \mathrm{P}=0.027$, respectively), and also longer arrest to search for a new direction (lateral movement of the thorax $)\left(\mathrm{F}_{1,28}=4.74 ; \mathrm{P}=0.039\right.$ and $\mathrm{F}_{1,28}=5.25 ; \mathrm{P}=0.030$, respectively).

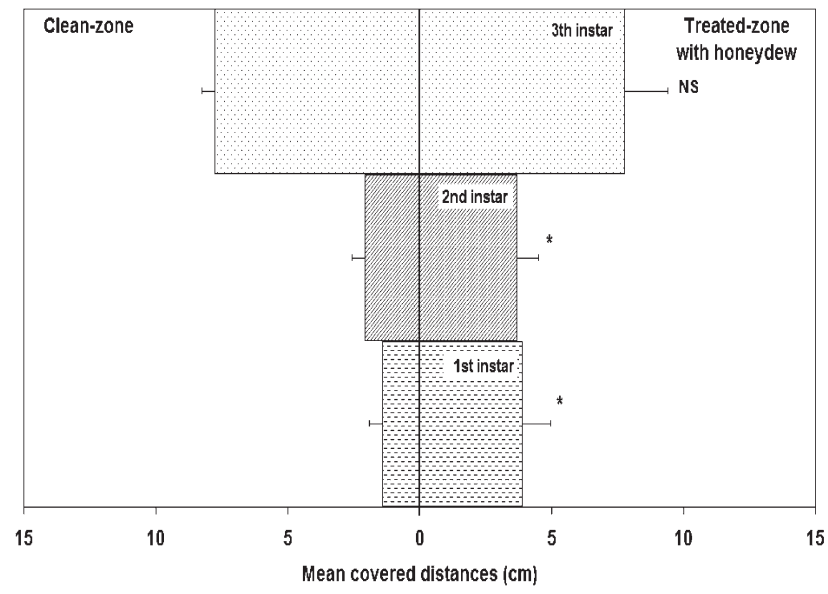

Fig. 2. Mean covered distances $(+\mathrm{SE})$ of E. balteatus larvae in response to the presence of honeydew in two-choice experiments. Asterisks indicate significant difference between treatments (One-way ANOVA: $\mathrm{P}<0.05$ ).

\section{Effect of aphid honeydew on the oviposition behaviour of syrphid female}

The foraging and oviposition behaviour of E. balteatus female was significantly influenced by the presence of aphid honeydew. The total times of "immobility", "searching", "acceptance" and "oviposition" were significantly greater on honeydew-treated plants $\left(\mathrm{F}_{1,28}=59.16 ; \mathrm{P}<\right.$ $0.001 / \mathrm{F}_{1,28}=58.04 ; \mathrm{P}<0.001$, respectively) (Fig. 4). We also found that $E$. balteatus females reduced the time spent for their behaviours "immobility" and "searching", in the presence of aphid honeydew on plant when compared to the clean plants (negative control) $\left(\mathrm{F}_{1,28}=60.07 ; \mathrm{P}<0.001\right.$ $/ \mathrm{F}_{1,28}=3.32 ; \mathrm{P}=0.048$ respectively). The number of eggs laid increased significantly in the presence of honeydew compared to control $\left(\mathrm{F}_{1,28}=30.07 ; \mathrm{P}=0.008\right)$ (Fig. 5).

\section{DISCUSSION}

In syrphids, female fecundity is positively related to the quality and quantity of aphids consumed during the larval stage (e.g. Almohamad et al., 2007, 2009). Infochemical cues emitted from aphids are also known to increase the foraging efficiency of predatory hoverfly larvae (Bargen et al., 1998; Francis et al., 2005). Chandler (1969) reported that aphidophagous hoverfly larvae start moving directly until their first tactile contact with aphids. We found that aphid honeydew acts as a foraging cue for E. balteatus larvae. Our behavioural observations show that the three larval instars exhibited distinct behavioural changes in response to the presence of $A$. pisum honeydew. The proportion of first or second instars of $E$. balteatus larvae arriving

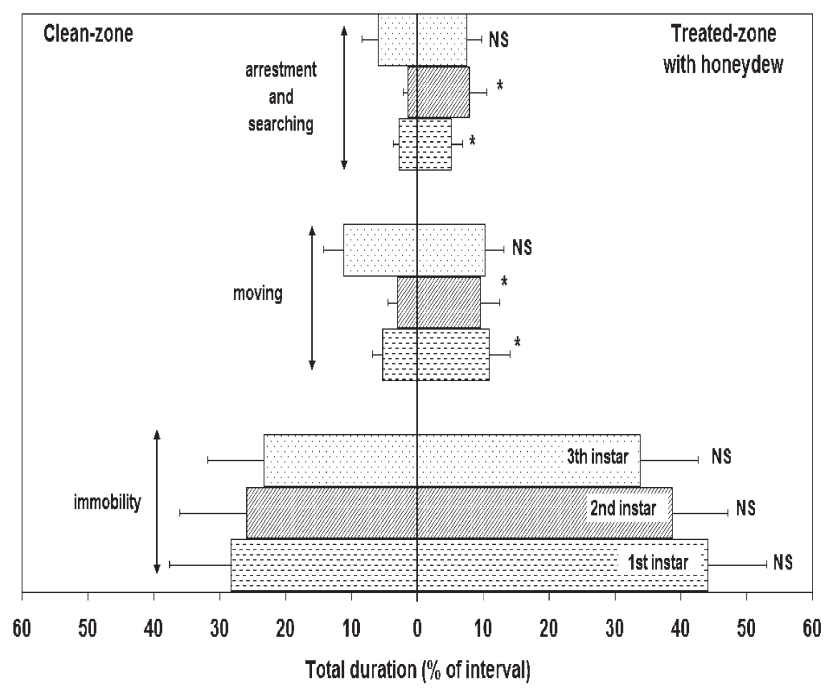

Fig. 3. \% Mean total durations ( $+\mathrm{SE})$ of behaviour of E. balteatus larvae in response to the presence of aphid honeydew in two-choice experiments. Asterisks indicate significant difference between treatments (One-way ANOVA: $\mathrm{P}<0.05$ ). 


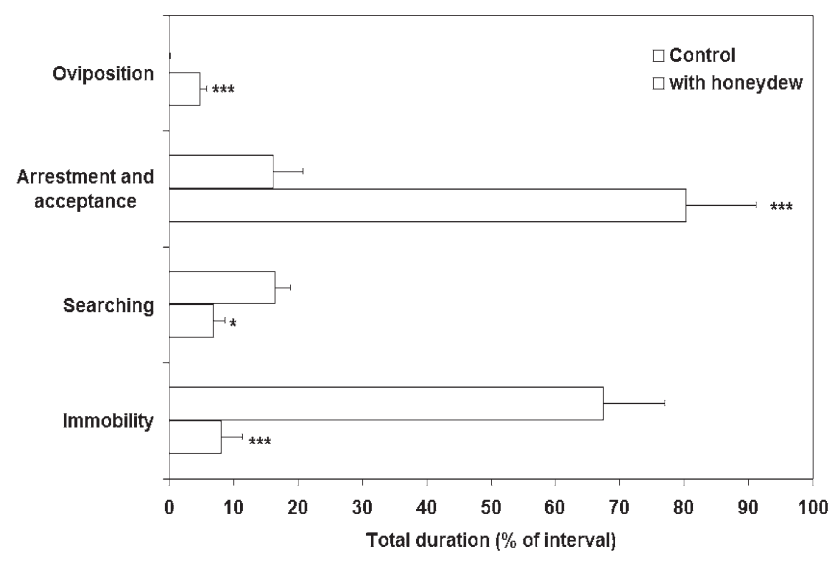

Fig. 4. \% Mean total durations (+SE) of behaviour of E. balteatus female in response to the presence of aphid honeydew in one-choice experiments. Asterisks indicate significant difference between treatments and control; (One-way ANOVA, Dunnett's test, $\mathrm{P}<0.05),{ }^{*} \mathrm{P}<0.05 ; * * * \mathrm{P}<0.001$.

at the zone contaminated with aphid honeydew was higher than that arriving at zone without aphid honeydew, and the frequencies of their behaviours (arrestment and casting) increased in response to the presence of honeydew. First instar larvae entered immediately into the aphid honeydew treated zone when introduced to the test arenas. These observations are consistent with the findings of Bargen et al. (1998) who suggested that the prey location of E. balteatus larvae may be guided by the aphid-born volatiles when searching for prey. There is evidence that E. balteatus larvae respond to olfactory volatile chemicals associated with different aphid species, (Acyrthosiphon pisum, Megoura viciae and Aphis fabae: Francis et al., 2005). Theory suggests that the intensified search (random, non directional search) in a small area helps the insect predator to find sufficient food if the prey is distributed in clusters (Murdie, 1972). Nevertheless, this behavioural mechanism is energy consuming and is not efficient enough to ensure high survival rates for first instar $E$. balteatus larvae which are unable to move any great distance (maximum about 1 m: Chandler, 1969). The ability to localize prey quickly is therefore an essential factor ensuring high survival for the vulnerable first instar larvae. Direct orientation of these larvae to aphid honeydew and induction of intensive search behaviour show that foraging behaviour in syrphid larvae has evolved to this critical situation. They could also possess learning and hens the ability to associate the presence of fresh honeydew with the presence of aphids.

The overall aggregation of syrphid larvae on honeydew seems to be caused by several different mechanisms: arrest, decreased walking speed (orthokinesis) and increased probing (klinokinesis). Honeydew therefore appears to be an arrestant and a contact kairomone for E. balteatus larvae, increasing the chance of contact with aphids. $E$. balteatus larvae may also use their mouthparts to detect substrates covered with honeydew before choosing their direction of travel. In this sense, Hood Henderson (1981) described contact chemosensilla close to the mouthparts of Metasyrphus venablesi which could be used to detect hon-

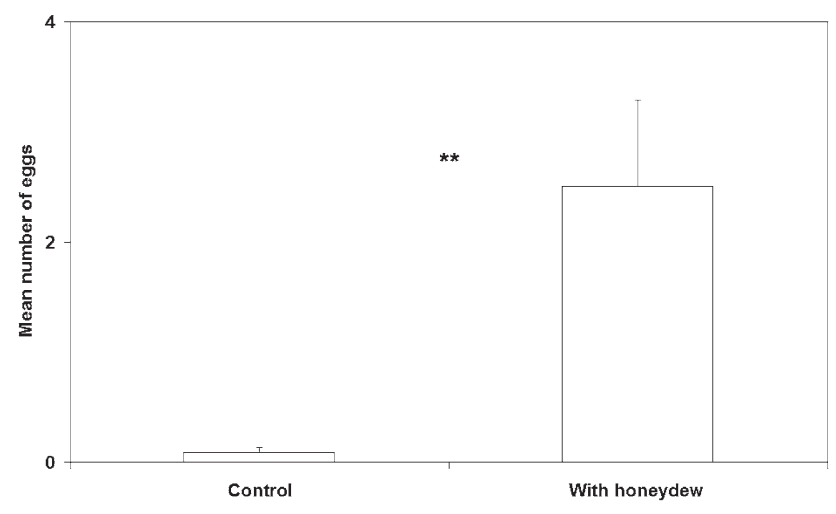

Fig. 5. Mean (+SE) number of syrphid eggs laid by the syrphid $E$. balteatus in response to the presence of A. pisum honeydew. Asterisks indicate significant difference between treatments and control; (One-way ANOVA, Dunnett's test, $* * \mathrm{P}<0.01$ ).

eydew. The fact that E. balteatus larvae use and perceive honeydew when foraging for aphids corresponds to behaviours seen in the larvae of the ladybird Coccinella septempunctata (Coleoptera: Coccinellidae) (Hagen, 1962; Carter \& Dixon, 1984; Ide et al., 2007), the green lacewing Chrysoperla carnea (Neuroptera: Chrysopidae) (Downes, 1974; Hogervorst et al., 2007) and the cecidomyiid Aphidoletes aphidimyza (Diptera: Cecidomyiidae) (Wilbert, 1974). Hogervorst et al. (2007) and Ide et al. (2007) also showed that $C$. carnea and C. septempunctata larvae use honeydew as a food complement even in the presence of aphids. In our study, E. balteatus larvae were observed to "insert" the anterior part of their basal sclerite into honeydew droplets before presenting suction movements. This particular behaviour was previously described by Ngamo \& Hance (1998) when larvae feed on aphids. Nevertheless, the utilisation of honeydew as a food source by $E$. balteatus larvae in the presence of aphid is still unknown, and further investigation is needed.

If aphid honeydew encounter acts as an attractant and arrestant cue for small E. balteatus larvae, then larvae foraging on the honeydew treated zone would frequently encounter a sticky surface compared with the rate on clean zone. Ide et al. (2007) found the proportion of ladybird larvae Coccinella septempunctata climbing a stick was higher if honeydew was present. Purandare \& Tenhumberg (2012) also reported that the Hippodamia convergens larvae were more likely to change from searching to resting/ feeding and remain in a resting/feeding state for a very long time in the presence of aphid honeydew. In our study, similar behaviour was shown, when larvae increased probing and decreased walking in contaminated zone. Larvae were also observed to insert their mouth parts into honeydew droplets, perhaps to use it as a food source. This particular behaviour (resting/feeding) shown by syrphid larvae may help them to avoid direct contact with a sticky matter. Small foraging syrphid larvae can have their mouth parts and delicate sense organs smeared with aphid honeydew, which can take time to clean off before starting a fresh search for food. This cleaning behaviour showed by foraging syrphid larvae may gave them time to move from 
the site of attack. According to Carter \& Dixon (1984), the amount of honeydew on a leaf did not influence the residence time of a Coccinella septempunctata larva on a leaf when aphids were present, and Ide et al. (2007) also suggested that larvae cease responding to honeydew once aphids are encountered. In the context of the observations of present study, the syrphid larvae use aphid honeydew as a contact kairomone when foraging for aphids, and the presence of aphids on plants could help them to avoid the response to the sticky aphid honeydew.

As a constrast, our results did not show any impact of aphid honeydew on the third instar larva. This could be explained by the fact that it is critical for young larvae to locate prey in order to survive and rapidly acquire energy, while older larvae merely have to feed periodically. Young larvae use honeydew as a contact kairomone to choose a direction while older larvae do not seem to care about the presence or absence of honeydew. After emergence from eggs, young larvae consume many aphids to gain in weight and size, and, during this period of time, they acquire and store energy allowing them to move greater distances. By the third instar, locating prey rapidly is less critical and does not compromise the survival of the larvae that have already accumulated nutrient reserves. This could explain why third instar larvae do not use honeydew as a kairomone since larvae are able to cover great distances to search for preys.

We confirmed that aphid honeydew is a key factor inducing gravid E. balteatus females to lay their eggs as reported in some previous studies (Bombosch, 1962, 1963; Volk, 1964; Scholz \& Poehling, 2000; Sutherland et al., 2001), and is used as an oviposition stimulant in the absence of aphids, as stated by Budenberg \& Powell (1992). Our observations also demonstrated that the overall time that females spent on honeydew treated plants is composed of several different behaviours: arrest, reduced immobility and searching and increased acceptance after arrestment and oviposition. Honeydew therefore seems to be an arrestant and a contact kairomone for E. balteatus adults, since they stop on plants to touch and perceive the substrate covered with honeydew using their proboscis and/or their ovipositor. This acceptance behaviour has been observed previously by several authors (Dixon, 1959; Budenberg \& Powell, 1992; Almohamad et al., 2007).

Our results indicate that both larvae and adults of $E$. balteatus respond to the presence of honeydew. It is interesting to draw a parallel between the relationships of both larvae and adults with honeydew. Indeed, if chemosensilla close to the mouthparts of larvae (Hood Henderson, 1981) might explain honeydew perception by larvae, the presence of chemosensilla close to the mouthparts and on the ovipositor of the adults allow honeydew perception by the adults. This strongly suggests that honeydew contains specific compounds perceived by larval and adult chemosensilla: perhaps specific sugars (synthesized by the aphids), specific amino acids (provided by the symbionts) or other specific compounds. This leads us to speculate that larvae and adults can learn to associate the presence of honeydew with the presence of aphids, indeed whatever is useful to locate prey or an appropriate oviposition site.

Our observations contribute to a better understanding of $E$. balteatus behaviour and show that aphid honeydew plays a key role for this aphid predator in both larval and adult stages. Further work will focus on identifying these honeydew compounds, and developing an artificial honeydew that could help enhance the efficiency of E. balteatus in biological control. The effect of honeydew as a kairomone on other insects should also be tested, given its wide availability to many insect species in natural environments.

ACKNOWLEDGEMENTS. We are deeply grateful to F. Gilbert from the University of Nottingham, School of Life Sciences, Nottingham, UK, for his English correction and valuable comments made to this manuscript. We also thank O. Decerf for his contribution to this work. This research was funded by the Walloon Region Ministry grant (WALEO2: SOLAPHIDRW/FUSAGX 061/6287).

\section{REFERENCES}

Almohamad R., Verheggen F., Francis F. \& Haubruge E. 2007: Predatory hoverflies select their oviposition site according to aphid host plant and aphid species. - Entomol. Exp. Appl. 125: $13-21$.

Almohamad R., Verheggen F., Francis F. \& Haubruge E. 2008a: Discrimination of parasitized aphids by a hoverfly predator: effect on larval performance, foraging and oviposition behavior. - Entomol. Exp. Appl. 128: 73-80.

Almohamad R., Verheggen F.J., Francis F., Lognay G. \& HauBRUGE E. 2008b: Emission of alarm pheromone by non-preyed aphid colonies. - J. Appl. Entomol. 132: 601-604.

Almohamad R., Verheggen F.J. \& Haubruge E. 2009: Searching and oviposition behavior of aphidophagous hoverflies (Diptera: Syrphidae): a review. - Biotech. Agron. Soc. Environ. 13: 467-481.

Almohamad R., Verheggen F.J., Francis F., Lognay G. \& HauBRUGE E. 2010: Assessment of oviposition site quality by aphidophagous hoverflies: reaction to conspecific larvae. - Anim. Behav. 79: 589-594.

Bargen H., Saudhof K. \& Poenling H.M. 1998: Prey finding by larvae and adult females of Episyrphus balteatus. - Entomol. Exp. Appl. 87: 245-254.

BнATIA M.L. 1939: Biology, morphology and anatomy of aphidophagous syrphid larvae. - Parasitology 31: 78-129.

Bombosch S. 1962: Studies on the stimulation of oviposition in Syrphus corollae Fabr. (Diptera, Syrphidae). - Z. Angew. Entomol. 50: 81-88.

Bомвоsсн S. 1963: Studies on the increase of Aphis fabae Scop. in seed-beet crops with special reference to hoverflies (Diptera, Syrphidae). - Z. Angew. Entomol. 52: 105-141.

BuCKLEY R.C. 1987: Interactions involving plants, Homoptera and ants. - Annu. Rev. Ecol. Evol. Syst. 18: 111-135.

BudenBerg W.J. 1990: Honeydew as a contact kairomone for aphid parasitoids. - Entomol. Exp. Appl. 55: 139-148.

Budenberg W.J. \& Powell W. 1992: The role of honeydew as an ovipositional stimulant for two species of syrphids. - Entomol. Exp. Appl. 64: 57-61.

Budenberg W.J., Powell W. \& Clark S.J. 1992: The influence of aphids and honeydew on the leaving rate of searching aphid parasitoids from wheat plants. - Entomol. Exp. Appl. 63: 259-264.

CARTER M. \& Dixon A.F.G. 1984: Honeydew: an arrestant stimulus for coccinellids. - Ecol. Entomol. 9: 383-387. 
Chandler A.E.F. 1968a: Some host-plant factors affecting oviposition by aphidophagous Syrphidae (Diptera). - Ann. Appl. Biol. 61: 412-423.

ChANDLER A.E.F. 1968b: The relationship between aphid infestations and oviposition by aphidophagous Syrphidae (Diptera). - Ann. Appl. Biol. 61: 425-434.

ChAndLer A.E.F. 1969: Locomotory behavior of first instar larvae of aphidophagous Syrphidae (Diptera) after contact with aphids. - Anim. Behav. 17: 673-678.

Dixon T.J. 1959: Studies on behaviour of Syrphidae (Diptera). Trans. R. Entomol. Soc. Lond. 112: 345-379.

Downes J.A. 1974: Sugar feeding by larva of Chrysopa (Neuroptera). - Can. Entomol. 106: 121-125.

Du Y., Guy M.P., Powell W. \& Wadhams L.J. 1997: Chemically mediated associative learning in the host foraging behaviour of the aphid parasitoid Aphidius ervi (Hymenoptera: Braconidae). — J. Insect Behav. 10: 509-521.

Evans E.W. \& Dixon F.G. 1986: Cues for oviposition by ladybird beetles (Coccinellidae): response to aphids. - J. Anim. Ecol. 55: $1027-1034$.

Evans E.W. \& Richards D.R. 1997: Managing the dispersal of ladybird beetles (Col.: Coccinellidae): Use of artificial honeydew to manipulate spatial distributions. - Entomophaga 42: 93-102.

Francis F., Martin T., Lognay G. \& Haubruge E. 2005: Role of (E)- $\beta$-farnesene in systematic aphid prey location by Episyrphus balteatus larvae (Diptera: Syrphidae). — Eur. J. Entomol. 102: 431-436.

GRIES G. 1986: Zum Beutefangverhalten der Schwebfliegenlarve Syrphus balteatus Deg. (Diptera, Syrphidae). - J. Appl. Entomol. 102: 309-313.

HaGen K.S. 1962: Biology and ecology of predaceous Coccinellidae. - Annu. Rev. Entomol. 7: 289-326.

Hatano E., Kunert G., Michaud J.P. \& Weisser W.W. 2008: Chemical cues mediating aphid location by natural enemies. - Eur. J. Entomol. 105: 797-806.

Heidari M. \& Copland M.J.W. 1993: Honeydew: A food or arrestant for the mealybug predator Cryptolaemus montrouzieri. - Entomophaga 38: 63-68.

Hogervorst D.E., Wäckers F.L. \& RomeIS J. 2007: Detecting nutritional state and food source use in field-collected insects that synthesize honeydew oligosaccharides. - Funct. Ecol. 21: 936-946.

Hood Henderson D.E. 1981: Responses of some Hoverflies to Oviposition Sites. Thesis, University of British Columbia, Vancouver, $180 \mathrm{pp}$.

Ide T., Suzuki N. \& Katayama N. 2007: The use of honeydew in foraging for aphids by larvae of the ladybird beetle, Coccinella septempunctata L. (Coleoptera: Coccinellidae). - Ecol. Entomol. 32: 455-460.

Leroy P.D., Wathelet B., Sabri A., Francis F., Verheggen F.J., Capella Q., Thonart P. \& Haubruge E. 2011: Aphid-host plant interactions: does aphid honeydew exactly reflect the host plant amino acid composition? - Arthropod Plant Interact. 5: 193 199.

McEwen P.K., Jervis M.A. \& Kidd N.A.C. 1993: Influence of artificial honeydew on larval development and survival in Chrysoperla carnea (Neur., Chrysopidae). - Entomophaga 38: $241-244$

Muratori F., Le Ralec A., Lognay G. \& Hance T. 2006: Epicuticular factors involved in host recognition for the aphid parasitoid Aphidius rhopalosiphi. - J. Chem. Ecol. 32: 579-593.

Murdie G. 1972: Problems of Data Analysis. In van Emden H.F. (ed.): Aphid technology. Academic Press, London and New York, pp. 295-318.
Ngamo T.L. \& Hance T. 1998: Functional morphology of the mandibles of the larvae of Episyrphus balteatus (De Geer, 1776) (Diptera: Syrphidae). — Int. J. Insect Morphol. Embryol. 27: $135-142$.

Petersen M.K. \& Hunter M.S. 2002: Ovipositional preference and larval - early adult performance of two generalist lacewing predators of aphids in pecans. - Biol. Contr. 25: 101-109.

Purandare S.R. \& Tenhumberg B. 2012: Influence of aphid honeydew on the foraging behavior of Hippodamia convergens larvae (Coleoptera: Coccinellidae). - Ecol. Entomol. 37: 184-192.

SAdEghi H. \& Gilbert F. 2000: Oviposition preference of aphidophagous hoverflies. - Ecol. Entomol. 25: 91-100.

Scholz D. \& Poenling H.M. 2000: Oviposition site selection of Episyrphus balteatus. - Entomol. Exp. Appl. 94: 149-158.

SHONoudA M.L. 1996: Crude aqueous-extract (kairomone) from Aphis fabae Scop. (Hom., Aphidae) and its effect on the behaviour of the predator Metasyrphus corollae Fabr. (Dipt., Syrphidae) female. - J. Appl. Entomol. 120: 489-492.

Shonouda M.L., Bombosch S., Shalaby A.M. \& Osman S.I. 1998a: Biological and chemical characterization of a kairomone excreted by the bean aphids, Aphis fabae Scop. (Hom., Aphididae), and its effect on the predator Metasyrphus corollae Fabr. I. Isolation, identification and bioassay of kairomone. J. Appl. Entomol. 122: 15-23.

Shonouda M.L., Bombosch S., Shalaby A.M. \& Osman S.I. 1998b: Biological and chemical characterization of a kairomone excreted by the bean aphids, Aphis fabae Scop. (Hom., Aphididae), and its effect on the predator Metasyrphus corollae Fabr. II. Behavioural response of the predator M. corollae. J. Appl. Entomol. 122: 25-28.

SHOREY H.H. 1977: Interactions of insects with their chemical environment. In Shorey H.H., Shorey J.J. \& Mckelvey J.J. (eds): Chemical Control of Insect Behavior. Wiley, New York, pp $1-5$.

Sutherland J.P., Sullivan M.S. \& Poppy G.M. 2001: Oviposition behaviour and host colony size discrimination in Episyrphus balteatus (Diptera: Syrphidae). - Bull. Entomol. Res. 91: 411-417.

Tenhumberg B. \& Poehling H.M. 1995: Syrphids as natural enemies of cereal aphids in Germany: aspects of their biology and efficacy in different years and regions. - Agric. Ecosyst. Environ. 52: 39-43.

Verheggen F.J., Arnaud L., Bartram S., Gohy M. \& Haubruge E. 2008: Aphid and plant volatiles induce oviposition in an aphidophagous hoverfly. - J. Chem. Ecol. 34: 301-307.

Verheggen F.J., Haubruge E., De Moraes C.M. \& Mescher M.C. 2009: Social enviroment influences aphid production of alarm pheromone. - Behav. Ecol. 20: 283-288.

VolK S. 1964: Studies on the oviposition of Syrphus corollae Fabr. (Diptera, Syrphidae). - Z. Angew. Entomol. 54: 365386.

WÄCKERS F.L. 2000: Do oligosaccharides reduce the suitability of honeydew for predators and parasitoids? A further facet to the function of insect-synthesized honeydew sugars. - Oikos 90: 197-201.

Wickeremasinghe M.G.V. 2007: Searching behaviour of the aphid parasitoid Aphidius rhopalosiphi (Hymenoptera: Aphidiidae) in response to honeydew excreted by aphids on different host plants. - Ruhuna J. Sci. 2: 89-95.

WILBERT H. 1974: The perception of its prey by newly hatched larvae of Aphidoletes aphidimyza (Cecidomyiidae). - Entomophaga 19: 173-181.

Received April 3, 2013; revised and accepted January 31, 2014 Prepublished online March 14, 2014 